\section{OP0028 EFFICACY AND SAFETY OF BCD-085, A NOVEL IL-17 INHIBITOR, IN ANKYLOSING SPONDYLITIS. RESULTS OF PHASE 2 CLINICAL STUDY}

V. Mazurov ${ }^{1}$, S. Erdes ${ }^{2}$, E. Kunder ${ }^{3}$, N. Soroka ${ }^{4}$, P. Shesternya ${ }^{5}$, S. Smakotina ${ }^{6}$, T. Raskina ${ }^{7}$, D. Krechikova ${ }^{8}$, T. Dubinina ${ }^{2}$, A. Eremeeva ${ }^{9}$, E. Dokukina $^{9}$, E. Chernyaeva ${ }^{9}$, R. Ivanov ${ }^{9} .{ }^{1}$ North-Western State Medical University named after I.I. Mechnikov, Saint-Petersburg; ${ }^{2}$ V.A. Nasonova Research Institute of Rheumatology, Moscow, Russian Federation; ${ }^{3}$ Clinical Hospital $1 ;{ }^{4}$ Clinical Hospital 9, Minsk, Belarus; ${ }^{5}$ Prof V.F. Voyno-Yasenetskiy Krasnoyarsk State Medical Univ, Krasnoyarsk, ${ }^{6}$ S. V. Belayev Kemerovo Regional Hospital; ${ }^{7}$ Kemerovo State Medical University, Kemerovo; ${ }^{8}$ Department Hospital at Smolensk Station of JSC 'Russian Railways', Smolensk, ${ }^{9} J C S$ BIOCAD, SaintPetersburg, Russian Federation

Background: BCD-085 is an innovative humanised monoclonal antibody against interleukin-17 with genetically modified Fc- and CDR-regions, aimed to improve treatment outcomes in patients with several autoimmune disorders.

Objectives: This abstract presents the results of double-blind placebo controlled dose-finding phase II clinical study of efficacy and safety of subcutaneous BCD085 in patients with ankylosing spondylitis.

Methods: The study was conducted as international multicenter randomised double-blind placebo controlled study. The study enrolled 88 adults with active AS. Patients were randomised in 4 study arms in 1:1:1:1 ratio to receive 40,80 or $120 \mathrm{mg}$ of BCD-085 or placebo. In the active period of the study, patients received the test drug/placebo SC injections once weekly for the first three weeks of treatment and then every other week till Wk 12. After Wk 12 all patients underwent follow-up for 4 weeks.

Results: Efficacy: BCD-085 is superior to placebo in doses 80 and $120 \mathrm{mg}$. ASAS20 at wk 16 was reached by $81.82 \%, 90.91 \%$ and $42.86 \%$ of patients in BCD-085 $80 \mathrm{mg}, 120 \mathrm{mg}$ and placebo arm respectively ( $\mathrm{p}=0.008,95 \% \mathrm{Cl}$ for difference in proportion [12.36\%; $65.56 \%]$; $p=0.001,95 \% \mathrm{Cl}: 23.71 \%$ to $72.39 \%]$, superiority margin $10 \%)$. Significant reduction of AS activity was revealed for all BCD-085 arms: by Wk 4 BASDAl and ASDAS-CRP scores decreased and maintained achieved levels till the end of the study. Other secondary endpoints (ASAS40, ASAS5/6, BASMI, BASFI, BASDAI, MASES, chest expansion, QoL, spinal pain) had the corresponding dynamics: by the time of second evaluation (Wk 1 for spinal pain, Wk 4 for other endpoints) significant improvement with no further negative changes was revealed. For all evaluated endpoints the most pronounced response was established for BCD-085 $120 \mathrm{mg}$ arm. In placebo arm no significant dynamics was shown.

Safety: All arms had highly similar safety profiles. Most of AEs were presented as mild or moderate laboratory abnormalities (ANC decreased, WBC increased) and moderate arterial hypertension. The rates of AEs were equivalent for all BCD-085 doses and placebo. There were no cases of SAEs, treatment discontinuation due to safety reasons or local reactions. Immunogenicity assessment did not detect formation of binding antibodies.

Abstract OP0028 - Table 1. Summarised safety data

\begin{tabular}{|c|c|c|c|c|c|}
\hline \multirow[t]{2}{*}{ Parameter } & \multicolumn{4}{|c|}{ Arm } & \multirow[t]{2}{*}{ P-value } \\
\hline & $\begin{array}{l}\text { BCD-085 } \\
40 \mathrm{mg} \\
(\mathrm{n}=22)\end{array}$ & $\begin{array}{c}\text { BCD-085 } \\
80 \mathrm{mg} \\
(\mathrm{n}=22)\end{array}$ & $\begin{array}{c}\text { BCD-085 } \\
120 \mathrm{mg} \\
(\mathrm{n}=22)\end{array}$ & $\begin{array}{c}\text { Placebo } \\
(\mathrm{n}=22)\end{array}$ & \\
\hline Any $\mathrm{AE}$ & $11(50.00 \%)$ & $6(27.27 \%)$ & $4(18.18 \%)$ & $7(31.82 \%)$ & 0.183 \\
\hline Therapy-related AEs & $5(22.73 \%)$ & $4(18.18 \%)$ & $1(4.55 \%)$ & $5(22.73 \%)$ & 0.354 \\
\hline Grade $3-4$ AEs & $1(4.55 \%)$ & $2(9.09 \%)$ & 0 & $1(4.55 \%)$ & 0.900 \\
\hline
\end{tabular}

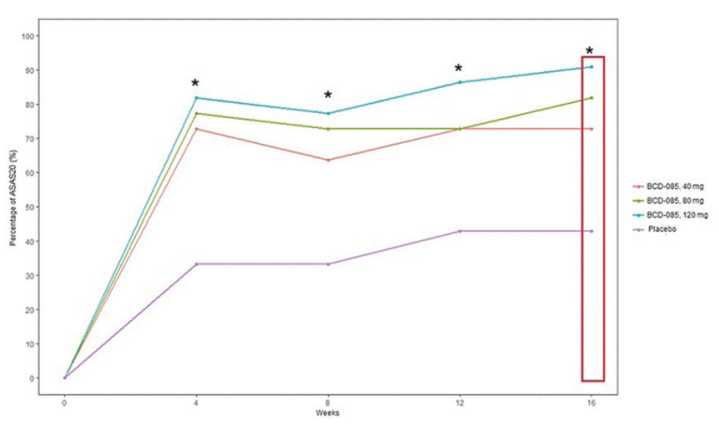

Abstract OP0028 - Figure 1. ASAS20 response throughout the study ${ }^{*}-$ statistically significant difference between BCD-085 and placebo arms).

Conclusions: Treatment with BCD-085 leads to significant improvement in all AS symptoms in comparison with placebo. The dose of $120 \mathrm{mg}$ of BCD-085 had the most pronounced effect. The drug was well tolerated in all doses with no differences with placebo in safety profiles.

Disclosure of Interest: V. Mazurov: None declared, S. Erdes: None declared, E. Kunder: None declared, N. Soroka: None declared, P. Shesternya: None declared, S. Smakotina: None declared, T. Raskina: None declared, D. Krechikova : None declared, T. Dubinina: None declared, A. Eremeeva Employee of: JSC BIOCAD, E. Dokukina Employee of: JSC BIOCAD, E. Chernyaeva Employee of: JSC BIOCAD, R. Ivanov Employee of: JSC BIOCAD

DOI: 10.1136/annrheumdis-2018-eular.2380

\begin{tabular}{|l|l}
\hline OP0029 & CLINICAL EFFECT OF VEDOLIZUMAB ON ARTICULAR \\
MANIFESTATIONS IN PATIENTS WITH \\
SPONDYLOARTHRITIS ASSOCIATED WITH \\
INFLAMMATORY BOWEL DISEASE
\end{tabular}

J. Paccou, M. Nachury, C. Duchemin, P. Desreumaux, R.-M. Flipo, B. Pariente. Lille University Hospital, Lille, France

Background: Data on the effects of vedolizumab on joint manifestations remain controversial. $^{1,2}$

Objectives: The purpose of this study was to evaluate baseline characteristics of crohn's disease (CD) and ulcerative colitis (UC) patients treated with vedolizumab, ${ }^{2}$ assess the effect of vedolizumab on joint manifestations in patients with inflammatory bowel disease (IBD)-associated Spondyloarthritis (SpA), and ${ }^{3}$ evaluate new onset of SpA under VDZ.

Methods: This single-centre, retrospective and observational study was conducted from July 2014 to July 2017. The charts of all patients with IBD who had undergone treatment with vedolizumab for more than 3 months were reviewed. The patients' demographic and clinical characteristics were collected. Data on IBD-associated SpA were collected as well as new onset of SpA under VDZ. The ASAS criteria were used to establish the diagnosis of SpA.

Results: Patient characteristics and main results are shown in table 1. A total of 171 patients diagnosed with IBD were treated with vedolizumab from July 2014 to July 2017. Notably, $97.1 \%$ of patients had been previously treated with at least one TNF- $\alpha$ inhibitor. All patients included in this study completed the induction phase at last observation, and the mean follow-up of the entire cohort was 14.3 \pm 12.0 months. Ten $(5.8 \%)$ patients had a history of IBD-associated SpA but were in clinical remission at the time of initiation of VDZ, whereas $4(2.4 \%)$ had active $\mathrm{SpA}$ when VDZ was started. First, no clinical benefit on SpA following initiation of VDZ was found in those 4 patients with active SpA. Second, exacerbation of SpA in patients with clinical remission at initiation of VDZ was found in 6/10 patients whereas no effect was reported in the remaining $4 / 10$ patients. All those 14 patients with IBD-associated SpA were under TNF inhibitors just before starting VDZ. Finally, new onset of SpA induced by VDZ was reported in 1 patient.

Abstract OP0029 - Table 1. Characteristics of patients and main results

\begin{tabular}{lc}
\hline Variable & $\mathrm{n}=\mathbf{1 7 1}$ \\
\hline Age (years), mean \pm SD & $37.8 \pm 12.9$ \\
Female gender, $\mathrm{n}(\%)$ & $110(64.3)$ \\
Body mass index $\left(\mathrm{kg} / \mathrm{m}^{2}\right)$, mean $\pm \mathrm{SD}$ & $23.7(4.8)$ \\
Type of disease, $\mathrm{n}(\%)$ & $104(60.8)$ \\
- Crohn's disease & $67(39.2)$ \\
- Ulcerative colitis & \\
Duration of disease (years), mean $\pm \mathrm{SD}$ & $10.5(7.6)$ \\
Duration of follow-up under vedolizumab (months), mean $\pm S D$ & 14.3 \\
& $(12.0)$ \\
IBD-associated SpA, $\mathrm{n}(\%)$ & $157(91.8)$ \\
- No history & $10(5.8)$ \\
- History (inactive at initiation of VDZ) & $4(2.4)$ \\
- Active at initiation of VDZ & \\
Clinical benefit on SpA following initiation of VDZ ( $=4)$ & $4 / 4(100)$ \\
- No clinical benefit & $0 / 4(0)$ \\
- Improvement & \\
Exacerbation of SpA in patients with clinical remission at initiation of VDZ & $6(60)$ \\
( $\mathrm{n}=10)$ & $4(40)$ \\
- Yes & \\
- No & \\
New onset of SpA induced by VDZ & $1(<1)$ \\
\hline
\end{tabular}

Conclusions: Vedolizumab does not seem to show any efficacy in IBD-associated SpA and might even induce exacerbation or new onset of SpA. Inception cohort studies are needed to better evaluate the effect of vedolizumab on joint manifestations.

\section{REFERENCES:}

[1] Varkas G, Thevissen K, De Brabanter G, et al. Ann Rheum Dis 2017 May;76(5):878-881. 